\title{
Association of acute equine leukoencephalomalacia (ELEM) with fumonisins concentrations in corn stover in an outbreak in the state of Jalisco, Mexico
}

\author{
Waldina P. Reyes-Velázquez ${ }^{\mathrm{a}^{*}}$, Claudia N. Anguiano-Sevilla ${ }^{\mathrm{b}}$, \\ Rubén Anguiano-Estrella ${ }^{\mathrm{b}}$, Federico G. Rojo ${ }^{\mathrm{c}}$
}

\begin{abstract}
Fumonisins are mycotoxins responsible for equine leukoencephalomalacia (ELEM) and they are produced by Fusarium species of high incidence in corn crops. In Jalisco (Mexico), six cases were confirmed by histopathological and neurological findings and fumonisins analysis. This is the first report of fumonisins in corn stover associated to ELEM cases.

Key words: fumonisins, corn stover, leukoencephalomalacia, horses.
\end{abstract}

Fumonisins (FBs) are secondary metabolites produced by Fusarium verticillioides and $F$. proliferatum and are responsible for equine leukoencephalomalacia (ELEM) (Marasas et al 1988). Fumonisin B1 (FB1), B2 (FB2) and B3 (FB3) are the most common in nature and are present in various cereals, mainly corn. ELEM is characterised by neurotoxic symptoms, initially with a sudden onset of depression, blindness and ataxia. Neurological examinations reflect severe damage to the brain. The histopathological findings are characterised by liquefactive necrosis of cerebral white matter, multiple foci of haemorrhage and edema (Osweiler 2001, Vendruscolo et al 2016). ELEM occurs after feeding horses with feedstuffs contaminated with FBs. Currently, there is no information on the natural occurrence of FBs in corn stover (dry corn stalk and leaves after ear of grain is removed) associated with ELEM, however, maize from Mexico is cultivated under different climatic conditions and FBs have been detected in grain and corn silage (Reyes et al 2008).

ELEM outbreaks have been reported in many countries, including Brazil, Argentina and the United States (Marasas et al 1988, Wilson et al 1990, Giannitti et al 2011). In México, an outbreak of ELEM was reported in the state of Oaxaca where 100 donkeys died. An analysis of 14 samples of corn enabled the detection of FB1 at levels between 0.67 and $13.3 \mathrm{mg} / \mathrm{kg}$. The histopathological findings showed liquefactive necrosis in the white matter of 3 donkeys brains (Rosiles et al 1998). In Jalisco, there have been several outbreaks but they have gone unpublished because the feed samples were not representative, and necropsies were not authorised due to sentimental value.

A presumptive ELEM diagnosis is based on clinical signs and as well as gross and histopathological findings

Accepted: 15.03.2018.

aDepartamento de Salud Pública, Centro Universitario de Ciencias Biológicas y Agropecuarias (CUCBA), Universidad de Guadalajara, México. bDepartamento de Producción Animal, Centro Universitario de Ciencias Biológicas y Agropecuarias (CUCBA), Universidad de Guadalajara, México.

${ }^{\mathrm{c} A s e s o r}$ Científico, Río Cuarto, Córdoba, Argentina

*Corresponding author: waldinareyes2@gmail.com
(Giannitti et al 2011). The confirmation of ELEM relies on the detection of FBs in feed ${ }^{1}$. However, ELEM is difficult to diagnose because the symptoms can mimic with other neurological syndromes. In Jalisco, possible causes include: trauma, toxic and illness such as Equine Protozoal Myeloencephalitis (EPM) and Wobbler syndrome.

This is the first report of fumonisins in corn stover associated with confirmed ELEM outbreak in Jalisco (Mexico) in 2012.

Six animals aged between 1.2 and 6 years from three localities in the state of Jalisco showed, between March and December 2012, characteristic clinical signs of a neurological disorder. According to the information collected, each equine received between 5 and $14 \mathrm{~kg}$ of daily dry matter (average $9.1 \mathrm{~kg}$ ) supplied twice a day, depending on age. Interestingly, all of the animals received at least $50 \%$ of corn stover (including corn kernel) supplemented with cracked corn (10\%) and feed concentrate (40\%) as ingredients that were oart of the total ration. All the animals died in less than a week.

To proceed with the brain specimen collection, formalin fixed paraffin embedded technique was used to obtain brain sections of $5 \mu \mathrm{m}$ thickness. These sections were stained with hematoxylin and eosin (HE) and mounted onto microscope slides.

Fumonisin B1 and B2 Analysis: Corn stover samples were obtained directly from horse stables. All samples were dried at $65{ }^{\circ} \mathrm{C}$ for $18 \mathrm{~h}$ (moisture content below 13\%), ground to a particle size of $1 \mathrm{~mm}$ and placed on polyethylene bottles. They were stored at $5 \pm 1{ }^{\circ} \mathrm{C}$ to prevent fungal growth. The analytical samples were analysed following the methodology by Shephard et al (1990) modified by Doko et al (1995) using precolumn derivatistion with o-phthal-dialdehyde (OPA) reagent and FLD-HPLC/RP. The separations were performed on a C18 column (150 x $4.6 \mathrm{~mm}, 5 \mu \mathrm{m})$. The mobile phase was methanol/ $0.1 \mathrm{M}$

Beasley V. 1999. Toxicants with mixed effects on the central nervous system. In: Beasley V (ed). Veterinary Toxicology. International Veterinary Information Service, Ithaca, NY, Document No. A2606.0899. Available at www.ivis.org 
dihydrogenated sodium phosphate solution (75:25) and the flow was $1.5 \mathrm{ml} / \mathrm{min}$. The $\mathrm{pH}$ of the solution was adjusted to 3.35 with orthophosphoric acid. The excitation and emission were 335 and $440 \mathrm{~nm}$, respectively.

The first criterion in our study was to describe the equine clinical signs and to rule out other disorders or illnesses. In most evaluated cases, neurological examination showed depression, blindness, ataxia, hyperexcitability, delirium, ambulation, profuse sweating, aggressiveness, pressure in the head (head reclined on the walls of the stable), prostration and seizures before dying. These symptoms are consistent with the description made by Foreman et al (2004) in horses exposed to Fumonisin B1 intravenously and cases reported by Vendruscolo et al (2016). Because of the multiple possible causes of neurological disorders, some veterinarians have requested studies to discard trauma or other significant illnesses. Diagnostic tests were done to determine Wobbler syndrome and Equine Protozoal Myeloencephalitis (EPM) by using x-ray and serological Western blot tests carried out by a third-party testing laboratory. Negative results were observed. In many countries, the differential diagnosis between different kinds of viral encephalitis is essential. In Mexico, the Venezuelan Equine Encephalitis has been eradicated. With regards to West Nile Virus and Equine Herpes Myeloencephalopathy, sporadic cases have been reported in the south of Mexico and also up north, in a neighbouring area to the United States, while no major problems were reported in Jalisco state.

Gross and histopathological findings in a quarter of a horse brain from tha locality Autlán de Navarro are shown in figure 1. Most of the observed injuries corresponded to edema and hemorrhagic foci. In relation to histophatological changes observed in central nervious system (CNS), the results showed liquefactive necrosis of the cerebral white matter, perivascular congestion, discrete spongiosis and gitter cells. These results are similar to those reported by Giannitti et al (2011) and Vendruscolo et al (2016) during ELEM outbreaks, and Marasas et al (1988) in induced cases by FB1-administration. No macroscopic injuries or trauma were reported in other organs.

In our study, the mean protein concentration in cerebrospinal fluid (CSF) was $197 \mathrm{mg} / \mathrm{dl}$ (normal value 20-124 mg/dl). This result is equivalent to that obtained by Foreman et al (2004) with induced neurologic disease by administration of FB1. In relation to the serum protein concentration, leukocytes and creatinine, the mean results were $38.5 \mathrm{~g} / \mathrm{dl}$ (normal value $7.5 \mathrm{~g} / \mathrm{dl}$ ), 13,500 cel/ $\mu \mathrm{l}$ (normal value $6,000-12,000 \mathrm{cel} / \mu \mathrm{l}$ ) and $1.9 \mathrm{mg} / \mathrm{dl}$ (normal value $0.5-1.7)$, respectively. These results showed mild changes respect to normal value indicating alteration in water balance, non-specific immune response, possibly due to inflammation and dehydration.

The total fumonisins (FBs) in feed and estimated intake by each animal are shown in table 1 . The highest contaminations were observed in Autlán de Navarro and Tamazula de Gordiano ( $>2$ times higher that FDA limits). These results agree with the study conducted by Sydenham et al (1992) and Ross et al (1991) during ELEM outbreak. Ross et al (1991) established that concentrations of FB1 associated with the development of ELEM were in the range of 1 to $126 \mathrm{mg} / \mathrm{kg}$. Although the lower FBs level was detected in Tlajomulco de Zuñiga, this result is in accordance with others reports confirmed ELEM cases (Sydenham et al 1992, Rosiles et al 1998). Our estimate of the minimal daily intake of the total fumonisins showed that the results are similar to Wilson et al (1992), and Foreman et al (2004), who reported values $0.06-0.18 \mathrm{mg} /$ $\mathrm{kg}$ /day (ponies fed with naturally FBs contaminated feed), and between $0.05-0.2 \mathrm{mg} / \mathrm{kg} /$ day (horses intravenously exposed to FB1), respectively. In addition, it should be
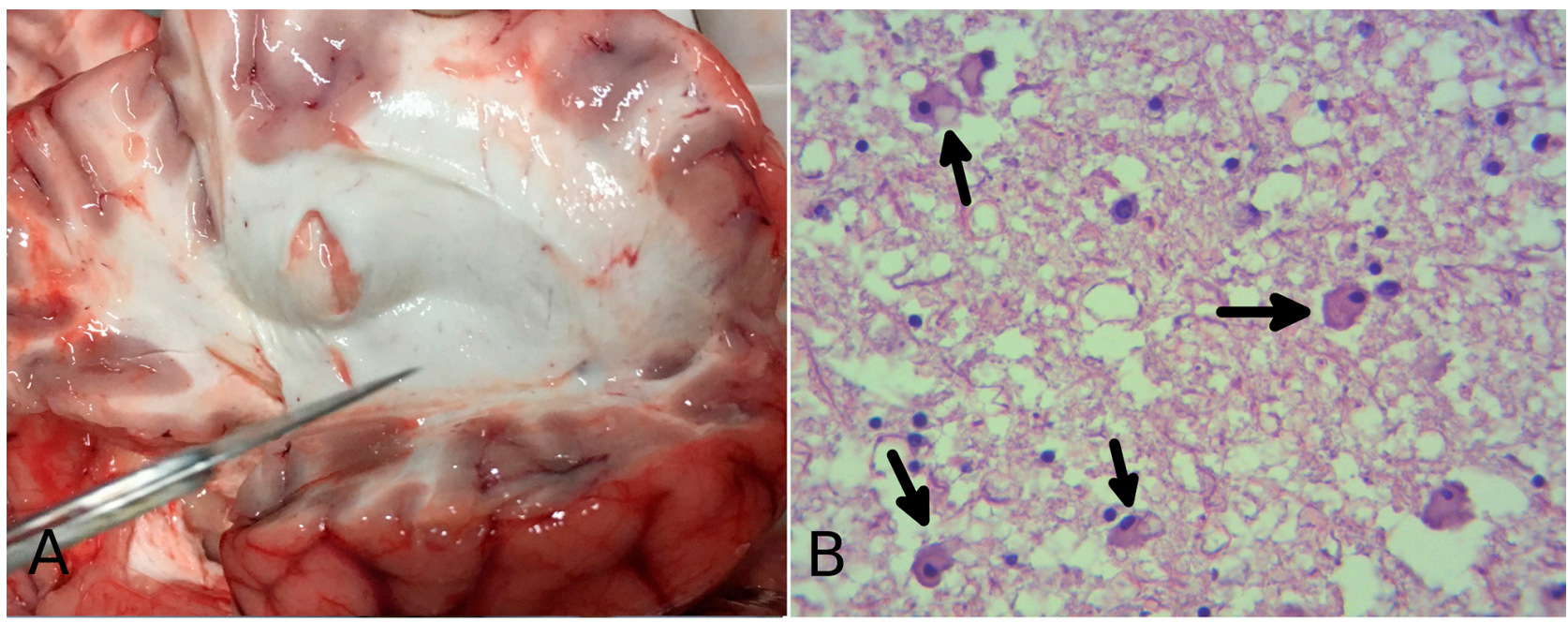

Figure 1. Lesions in the brain of horse with equine leukoencephalomalacia (ELEM) from the locality Autlán de Navarro, Jalisco State (2012). A: Gross examination of the brain showing liquefactive necrosis of white matter. B: Severe vacuolization, moderate necrosis in the white matter and presence of gitter cells (arrows, HE 600x). 
Table 1. Data collected for equine leukoencephalomalacia (ELEM) cases subdivided by Localities in Jalisco State with primary examination findings and concentrations of total fumonisins (FBs = FB1 + FB2) found in corn stover.

\begin{tabular}{|c|c|c|c|c|c|c|c|c|}
\hline Localities & Breed & Sex & Age & $\begin{array}{l}\text { Weight } \\
(\mathrm{kg})\end{array}$ & $\begin{array}{c}\text { Mean Total Fumonisins } \\
\text { (FBs; } \mathrm{mg} / \mathrm{kg} \text { ) } \\
\text { in corn stover }\end{array}$ & $\begin{array}{l}\text { Corn stover } \\
(\%) \text { in ration }\end{array}$ & $\begin{array}{l}\text { Minimun level } \\
\text { FBs en ration } \\
(\mathrm{mg} / \mathrm{kg}) *\end{array}$ & $\begin{array}{c}\text { Estimated } \\
\text { Intake FBs } \\
(\mathrm{mg} / \mathrm{bw} \mathrm{kg} / \text { day })\end{array}$ \\
\hline \multirow[t]{3}{*}{ Autlán de Navarro } & Quarter Horse & $\mathrm{F}$ & 3.3 & 485 & 4.54 & 50 & 2.27 & 0.04 \\
\hline & Quarter Horse & $\mathrm{F}$ & 4.3 & 492 & & & & 0.04 \\
\hline & Quarter Horse & $\mathrm{F}$ & 1.2 & 342 & & & & 0.09 \\
\hline \multirow[t]{2}{*}{ Tamazula de Gordiano } & Frizian & M & 4 & 520 & 5.23 & 50 & 2.62 & 0.05 \\
\hline & Espanol & M & 6 & 495 & & & & 0.05 \\
\hline Tlajomulco de Zuñiga & Pony & $\mathrm{F}$ & 4 & 225 & 1.80 & 50 & 0.90 & 0.02 \\
\hline
\end{tabular}

References: FDA = U.S. Food and Drug Administration; F = Female, M = Male; bw = body weight; * Maximum allowable FBs levels by FDA: $<5$ mg/ $\mathrm{kg}$ up no more than $20 \%$ of the dry weight of total ration $(1 \mathrm{mg} / \mathrm{kg}$ equine feed).

noted that mycotoxins are not uniformly distributed and the analytical samples were taken directly from the feeder. In conclusion, our histopathological and neurological findings in equine with ELEM signs, in addition to fumonisins exposure levels agree with previous studies on confirmed cases. This report underlines the importance of monitoring corn stover as another source of exposure to fumonisins. The FBs levels in corn stover and feed would enable the identification of high-risk areas for ELEM occurrence in Jalisco.

\section{ACKNOWLEDGEMENTS}

This work was supported by the Universidad de Guadalajara. The authors would like to thank Dr. David Ávila Figueroa for his work during the histopathological image analysis.

\section{REFERENCES}

Doko B, Rapior S, Visconti A, Schjoth J. 1995. Incidence and levels of fumonisins contamination in maize genotypes grown in Europe and Africa. J Agric Food Chem 43, 429-434.

FDA/CFSAN, Food and Drug Administration, Center for Food and Applied Nutrition. 2001. Guidance for Industry. Fumonisin levels in human foods and animal feeds.

Foreman J, Constable P, Waggoner A, Levy M, Eppley R, et al. 2004. Neurologic abnormalities and cerebrospinal fluid changes in horses administered fumonisin B 1 Intravenously. J Vet Intern Med 18, 223-230.
Giannitti F, Diab S, Pacin A, Barrandeguy M, Larrere C, et al. 2011. Equine leukoencephalomalacia due to fumonisins B1 and B2 in Argentina. Pesq Vet Bras 31, 407-412.

Marasas WFO, Kellerman TS, Gelderblom WCA. 1988. Leukoencephalomalacia in a horse induced by Fusarium moniliforme B1. Onderstepoort J Vet Res 55, 197-203.

Osweiler GD. 2001. Micotoxins. Vet Clin North Am Equine Pract 17, 547-566.

Reyes-Velazquez W, Espinoza V, Rojo F, Plasencia C, Palacios E, et al. Occurrence of fungi and mycotoxins in corn silage, Jalisco State, Mexico. 2008. Rev Iberoam Micol 25, 182-185

Rosiles MR, Bautista J, Fuentes VO, Ross F. 1998. An outbreak of Equine Leukoencephalomalacia al Oaxaca, Mexico, associated with Fumonisin B1. J Vet Med A 45, 299-302.

Shephard GC, Sydenham EW, Thiel PG, Gelderblom WCA. 1990. Quantitative determination of fumonisins B1 and B2 by high-performance liquid chromatography with fluorescence detection. J Liq Chromatogr 13, 2077- 2080.

Sydenham E, Marasas W, Shephard G, Pieter G, Thie1 P, et al. 1992. Fumonisin concentrations in brazilian feeds associated with field outbreaks of confirmed and Suspected Animal Mycotoxicoses. $J$ Agric F\& Chem 40, 994-997.

Vendruscolo CP, Frías NC, de Carvalho CB, de Sá LRM, Belli CB, et al. 2016. Leukoencephalomalacia outbreak in horses due to consumption of contaminated hay. J Vet Intern Med 30, 1879-1881.

Wilson TM, Ross PF, Rice LG, Osweiler GD, Nelson HA, et al. 1990. Fumonisin B1 levels associated with an epizootic of equine leukoencephalomalacia $J$ Vet Diagn Invest 2, 213-216.

Wilson TM, Ross PF, Owens DL, Rice LG, Green SA, et al. 1992. Experimental reproduction ELEM. A study to determine to mínimum toxicdose in ponies. Mycopathologia 117, 115-120. 
